\title{
Long term health-related quality of life after burns is strongly dependent on pre-existing disease and psychosocial issues and less due to the burn itself
}

Lotti Orwelius, M Willebrand, B Gerdin, L Ekselius, Mats Fredrikson and Folke Sjöberg

\author{
Linköping University Post Print
}

\section{Tweet}

N.B.: When citing this work, cite the original article.

Original Publication:

Lotti Orwelius, M Willebrand, B Gerdin, L Ekselius, Mats Fredrikson and Folke Sjöberg, Long term health-related quality of life after burns is strongly dependent on pre-existing disease and psychosocial issues and less due to the burn itself, 2013, Burns, (39), 2, 229-235. http://dx.doi.org/10.1016/j.burns.2012.11.014

Copyright: Elsevier

http://www.elsevier.com/

Postprint available at: Linköping University Electronic Press

http://urn.kb.se/resolve?urn=urn:nbn:se:liu:diva-91552 


\section{Long term Health - Related Quality of Life after burns is strongly dependent on pre-existing disease and psychosocial issues and less due to the burn itself}

Orwelius L ${ }^{1}$, Willebrand M. ${ }^{2}$, Gerdin B. ${ }^{3}$, Ekselius L. ${ }^{2}$, Fredrikson M. ${ }^{4}$, Sjöberg F. ${ }^{1,4,5}$

${ }^{1}$ Department of Intensive Care, Linköping University Hospital, , ${ }^{2}$ Department of

Neuroscience, Psychiatry, Uppsala University, Uppsala, Sweden, ${ }^{3}$ Department of Surgical

Sciences, Plastic Surgery, Uppsala University, Uppsala, Sweden, ${ }^{4}$ Department of Clinical and

Experimental Medicine, Linköping University, Linköping Sweden, ${ }^{5}$ The burn unit, Depts. of

Hand and Plastic Surgery, Linköping University hospital, Linköping, Sweden

\section{Corresponding author}

Lotti Orwelius, $\mathrm{PhD}, \mathrm{CCRN}$

Department of Intensive Care

Linköping University hospital

SE-581 83 Linköping, SWEDEN

lotti.orvelius@lio.se

Telephone: +46 010- 1033651

Fax; +46 010-103 8649

None of the authors have any financial interests to disclose.

Original article 


\section{Abstract}

Background Health-related quality of life (HRQoL) is reduced after a burn, and is affected by coexisting conditions. The aims of the investigation were to examine and describe effects of coexisting disease on HRQoL, and to quantify the proportion of burned people whose HRQoL was below that of a reference group matched for age, sex, and coexisting conditions.

Method A nationwide study covering 9 years and examined HRQoL 12 and 24 months after the burn with the SF-36 questionnaire. The reference group was from the referral area of one of the hospitals.

Results The HRQoL of the burned patients was below that of the reference group mainly in the mental dimensions, and only single patients were affected in the physical dimensions. The factor that significantly affected most HRQoL dimensions $(n=6)$ after the burn was unemployment, whereas only smaller effects could be attributed directly to the burn.

Conclusion Poor HRQoL was recorded for only a small number of patients, and these were mostly in the mental dimensions when compared with a group adjusted for age sex, and coexisting conditions. Factors other than the burn itself, such as mainly unemployment and pre-existing disease, were most important for the long term HRQoL experience in these patients.

Key words: Health related quality of life; burn injury; pre-existing disease; control group; comorbidity; long term; SF-36; unemployment. 


\section{Introduction}

Burned patients have often been found to have altered health-related quality of life (HRQoL) when they are examined after the injury and compared with healthy control groups $(1,2,3)$. The reasons include the burn itself together with pre-existing factors, most importantly coexisting disease, age, sex and psychiatric morbidity (4-6). However, the specific effects of coexisting diseases by e.g., comparisons with a comorbidity adjusted control group have to our knowledge not been examined before. In a recent single-centre investigation our research group showed that two-thirds of the burned patients had long term psychiatric morbidity assessed by a structured clinical interview (5). Therefore, such an adjustment seems important to better understand the HRQoL decline.

Coexistent morbidity also affects HRQoL among patients treated in medical or surgical intensive care (ICU) (7). We therefore hypothesised that pre-existing morbidity is a major factor that affects the HRQoL experienced by patients who have been treated for burns.

The aims of this study were to assess HRQoL 12 and 24 months after severe burns to evaluate to what extent, and in which domains, they differed from a control group matched for age, sex, and coexisting conditions, and also to evaluate factors before and after injury, such as comorbidity, sick leave, and unemployment, that are known to affect HRQoL. HRQoL was assessed with the generic instrument SF-36 (8), which is known to address most dimensions, including mental health.

\section{Patients and Methods}




\section{Patients}

This prospective, longitudinal, national, two-centre study took place at the two national burn centres in Sweden (Linköping and Uppsala), each of which admits roughly 100-120 patients/year. Admission criteria were based on the recommendations of the American Burn Association (9). The referral area for the two centres includes about 9 million inhabitants.

We studied patients who were admitted consecutively for treatment of burns at the Uppsala Burn Centre between 28 March 2000 and 31 March 2009 and at the Linköping Burn Centre between 1 November 2002 and 31 December 2009. At the Uppsala Burn Centre the patients were part of an ongoing prospective study with inclusion during the initial acute treatment at the hospital and follow-up assessments at 3, 6, and 12 months after the burn injury. Only the data from the 12month assessment were considered in this study and as a supplement for this study a 24-month assessment was undertaken. At the Linköping Burn Centre, all patients admitted during the specified time period were assessed 12 and 24 months after the burn injury. The inclusion criteria for both centers were; Swedish speakers aged 18 years or over and; either burns $\geq 10 \%$ of total body surface area (TBSA \%) or duration of stay in the burns unit of 7 days or more.

All patients admitted during the specified period were approached on the ward or by mail 12 and 24 months after the burn. The letter included information about the study, a structured questionnaire, and a stamped addressed envelope. For those patients who were approached by mail and had not responded within about 10 days were contacted by telephone by one of the investigators (LO). If telephone or first mailing achieved no answer two reminders were sent out (at 3 and 6 weeks).

The clinical databases in each burn centre were used to extract data on age, sex, TBSA\%, full thickness total surface area \% (TBSA-FT \%), duration of stay in ICU, and time spent on the ventilator. 
Data from a public health survey of the county of Östergötland (the area in which one of the burn centres is situated) were used for comparison of HRQoL and coexisting conditions. That survey had been undertaken to monitor the general health of the population in a different study and was completed during 1999 (10). Questionnaires were initially sent out to 10000 people aged 18 to 74 years. After two reminders, $6093(61 \%)$ had responded (10).

The study followed the principles of the Helsinki Declaration and was approved by both the Linköping University and the Uppsala University Hospital ethics committees.

\section{Questionnaires and instruments}

A set of structured questionnaires were sent to the study group 12 and 24 months after the injury. The questionnaire contained questions about the patient's background: employment, on sick leave or not, level of education, marital state, pre-existing disease, and self-reported diagnoses.. The questionnaire about the self-reported diagnoses asked, "Have you had any significant illness, reduced bodily function or other medical problem, and had it for more than 6 months before admission to the ICU?" with the option to answer "yes" or "no". This question also listed possible pre-existing illnesses: "cancer; diabetes; heart failure; asthma or allergy; rheumatic, gastrointestinal, blood, kidney, psychiatric, or neurological disease; thyroid or any other metabolic disturbance; or any other long- term illness". The last was an open question with a slot for free text. For Uppsala patients the pre-existing diseases were collected from the medical records by one of the doctors in the research group (BG).

The Swedish version of Medical Outcome Short Form $(\mathrm{SF}-36)(8,11)$ was chosen to evaluate HRQoL. The instrument is internationally known and has been recommended for assessment of HRQoL in critical care (12). SF-36 has been validated in a 
representative Swedish sample (11), and in the burn population (13). It has 36 questions and generates a health profile of eight subscale scores whereof 4 subscales relate to the physical dimensions (physical functioning, physical role; bodily pain, or general health), and 4 subscales relate to the mental dimensions (vitality, social functioning, emotional role, or mental health) (11). The scores of all the subscales are transformed into a scale ranging from 0 (the worst) to 100 (the best).

Data about psychiatric morbidity assessed by the Structured Clinical Interview for the DSM-IV Axis I disorders (SCID-I) (14) was available in a subsample (5).

The questionnaire sent to the reference group in 1999 included questions on background characteristics as above, HRQoL (SF-36 questionnaire), and questions about health problems. Details and the method for this part has been published previously (15).

\section{Statistics and calculations}

We used an extensive "normal" group to construct the normal range for SF-36 values to which to compare the data (mean (2SD)) from each burned patient. Since -2SD sometimes resulted in a minus number in the model; the lower $2.5 \%$ was used as proxy for $-2 \mathrm{SD}$. The comparison was built on a model for the control group in which one dimension of SF-36 at a time was the dependent variable in a linear regression model, and age and sex were independent variables. This was performed separately for no, one, and more than one previous diseases. The coefficients from that analysis were then used to calculate each patient's value adjusted for age and sex. This calculated value was compared with the values from the control group. This approach made it easier to identify the number of burned patients who had "subnormal" values for HRQoL, that is, less than the reference group lower than $-2 \mathrm{SD}$ value in each dimension. 
Data are presented as mean (SD). Unadjusted two-sample comparisons (chi square and Student's $t$ test) were used as appropriate to assess differences in background characteristics between the groups. In the comparison of HRQoL (SF-36) between the reference group and the study group on different occasions (12 and 24 months), the paired Students $t$-test was used and when examining differences between the patients (12 and 24 months) and the unpaired Student's $t$-test when examining differences between the patients and the control group (12 months). . The lower level (-2SD) in each dimension of SF-36 for the reference group was used for comparison. A multiple linear regression analysis, adjusted for age and sex, was used to analyse the independent effects of burn-related factors (TBSA\%; TBSA FT\%; duration of hospital stay; and time on ventilator) pre-existing conditions; time on sick leave; present employment; level of education; and marital state. To maximise the statistical power, the 12-month follow-up data was used $(n=172)$. In analyses in which HRQoL was compared over time, only participants who responded to both follow up questionnaires were used $(n=75)$. No adjustments for multiple testing were made and probabilities were regarded as descriptive. Probabilities of less than 0.05 were accepted as significant.

Variables with probabilities of less than 0.05 in the regressions were included in final stepwise linear multiple regressions with each of SF-36 subscales as dependent variables.

The Statistical Package for the Social Sciences (PASW, version 18.0, Chicago, IL. USA) was used to aid the statistical analyses. 


\section{Results}

\section{Patients}

During the study period 2000 to 2009, 266 patients fulfilled the inclusion criteria. Of these, 55 were lost to follow up, 41 declined to participate (32 in the Linköping sample and 9 in the Uppsala sample), and 14 were lost for administrative reasons (Uppsala sample). A total of 156 patients therefore participated at the 12-month assessment (40 women and $116 \mathrm{men}$ ), and 75 in the 24 month assessment (23 women and 52 men). In addition, four patients died during the study (three in Linköping and one in Uppsala), and 48 dropped out of the study between the 12 and 24 months follow-up (34 in the Linköping sample and 14 in the Uppsala sample).

\section{Social and personal data}

Social and personal data for responders $(n=156)$ and non-responders $(n=101)$ together with the reference group $(n=6093)$ are shown in Tables 1 and 2. Apart from more patients in higher education recorded at the Linköping centre, there were no significant differences in the study groups at the two centres (age, sex, duration of stay, TBSA \%, TBSA FT\%, and time on ventilator) (data not shown). There were no significant differences between the responders and the non-responders, except that the responders had larger TBSA\% (Table 1).

In the study population $71(46 \%)$ patients had pre-existing conditions at least 6 months before the injury, the most common of which were related to psychiatric or psychological issues $(\mathrm{n}=22,14.1 \%)$ compared with $99(1.6 \%)$ for the reference group. The overall number of coexisting conditions in the reference group was 1707 (28\%)(Table 2). 


\section{Health-related quality of life}

HRQoL among the burned patients was significantly affected in all dimensions both at 12 and 24 months, except for bodily pain $(\mathrm{p}=0.17)$ and vitality $(\mathrm{p}=0.07)$ at 24 months (Figure 1) compared with the reference group. For the burned patients, improvements were recorded in only two dimensions (physical functioning, physical role,) between 12 and 24 months. It needs to be stressed that the improvement in physical function and role physical where more than a 5 point score change (the HRQoL score magnitude needed for a clinical significant change (16)).

\section{Comparison of the burned patients with the reference group adjusted for age, sex, and coexisting conditions (Tables 3 and 4 )}

When the burned patients without pre-existing disease $(n=85)$ were compared with the healthy reference group ( $n=4386$ ), fewer than $5 \%$ of the patients had values below the lower reference group value (-2 SD) in any of the physical dimensions (physical functioning, physical role, bodily pain, and general health). In the mental dimensions (vitality, social functioning, emotional role, and mental health), $8 \%$ to $34 \%$ of the patients had a value below the lower reference group value (-2 SD) (Table 3).

Fewer than $2 \%$ of the burned patients with one pre-existing disease $(n=60)$ had values below the reference group value (-2SD) when compared with the corresponding reference group (one coexisting condition) $(n=1411)$ in any of the physical dimensions. In the mental dimensions, 5\%-22\% depending on the dimension were recorded below the reference group value (Table 3).

When we compared the burned patients with more than one co-existing condition $(n=11)$ with the corresponding number in the reference group ( $>1$ coexisting 
condition, $\mathrm{n}=296$ ), 0 to $18 \%$ of the patients had values below the lower reference group value (-2 SD) depending on dimension (Table 3).

When we compared descriptive data between burned patients with normal HRQoL and those with lower HRQoL, those with low HRQoL had more severe burns (as assessed by TBSA-FT \%, duration of stay in ICU, and time on ventilator) (Table 4).

\section{Clinical and psychosocial factors important for HRQoL values recorded in burned patients (Tables $5 \mathrm{a}$ and $5 \mathrm{~b}$ )}

Important factors associated with the HRQoL after burns on multiple regression were: current unemployment, associated with six dimensions (physical functioning, bodily pain, general health, vitality, emotional role, and mental health); duration of stay in hospital (physical role, general health, and social functioning); and pre-existing disease, both latter with three dimensions (general health, vitality, and mental health) (Table 5a and 5b). Finally, TBSAFT\% with two dimensions (physical functioning, and vitality) (Tables 5a and b)

\section{Discussion}

The novelty of this study is that it examines the proportion of burned patients who have HRQoL that is less than that of the reference group adjusted for age, sex, and (most importantly) coexisting condition. There are several new and important findings:

Firstly, and the major finding in this study is that after adjustments are made (age, sex and co-morbidity) the most extensive effect on the HRQoL dimensions ( $n=6$ ) was that of unemployment.

Secondly,, for two levels of coexisting condition (healthy and one condition) only small effects in the physical dimensions were recorded. The group with more than one coexisting condition was so small that any conclusions were considered less valid. 
Third, a different picture is evident for the mental dimensions for which between $5 \%$ and $34 \%$ of the patients fell below the lower level (-2SD) of the reference group. Most of these observations were recorded in the previously healthy group. The lower levels of HRQoL may therefore be the result of the burn, or an undiagnosed problem such as a permanent psychiatric or psychological condition. In a subgroup of our patients it has been shown that the prevalence of long-term psychiatric morbidity is high $(27 \%)$. We assume that there is also an underreporting of psychiatric/psychological issue from the pre injury period that affect our results.

Fourth, when we look at HRQoL and do not take the coexisting condition into account, (Table 4) the group of patients who have HRQoL that is worse than -2 SD of the reference group also have the most effects from burn-related factors. When adjustment is made for coexisting conditions the effects is significantly attenuated. This suggests that patients with coexisting conditions may have worse burns. This needs to be explored further.

Fifth, factors related to the burn had only minor effects on HRQoL and of these, length of stay and TBSA-FT \% were important in only a few dimensions, mostly related to physical function.

Sixthly, improvements over time after the injury were recorded in only two of eight dimensions of the SF-36, mainly in the physical dimensions.. These data support the hypothesis that burned patients may perceive a lower mental health already before the burn injury when compared with a control group adjusted for age, sex, and coexisting conditions. It then needs to be stressed that there is in this study an over-representation of coexisting psychiatric morbidity $(27 \%)$. Such a finding has previously been repeatedly reported by others $(5,17,18)$. We also think that the $27 \%$ is a falsely low figure, as it is well known that 
psychiatric-related problems are under-reported by patients (19). Furthermore, the present finding that unemployment was important for the HRQoL registered after the burn, also has relevance to the psychiatric and psychological issues listed, as it is well known that unemployment is more common among people with psychiatric and/or psychological problems or long-term psychiatric morbidity. It has been well-documented that such psychosocial factors have a strong impact on health-related HRQoL (2-4). We also think that a larger proportion of the lower values in the mental dimensions relate to such issues rather than being secondary to the burn. This needs to be further examined, by not adjusting categorically (previously healthy, one or more than one disease) for pre-existing conditions but rather to adjust for specific diseases. The results emphasise that issues not primarily related to the burn are important for the outcome for patients with burns.

We think that the findings in the present study may also be true for other areas of the western world. The uptake areas of the two burn units correspond to roughly10 million inhabitants, although the prevalence of burns is somewhat lower in Sweden than other western countries (20); the types of burn seen in the two units are similar, and the outcome variables are homogeneous in a country that comprises both urban and rural areas.

\section{Limitations}

The use of a relevant reference group is strength of this study. However, the comparison may be somewhat compromised by the fact that the coexisting conditions in the reference group differed significantly from those among the burned patients. In the latter group self-reported psychiatric diseases were 8 times more common, and the co-morbidity profile of the reference group contains more cardiovascular and gastrointestinal conditions (7). This emphasises that the type and extent of coexisting conditions may also be important when choosing a relevant control group. 
The patients that answered the questionnaires had a larger TBSA\% than those that did not. This could affect the results and the conclusions made. However, the absolute difference was restricted compared with the overall burn sizes observed, i.e., $5 \%$. Also several of our analyses depended on regression models in which TBSA\% was examined and adjusted for. Therefore, we do not think this difference has any significant impact on our conclusions.

Also the reference group was examined in 1999 whereas the burn study ended 10 years later. This could possibly affect the results and the conclusions made. However, we are not aware of any social or demographic changes in this time period that could affect our conclusions. We therefore think that the conclusions drawn are not significantly affected by this time period difference.

\section{Conclusions}

Small improvements were recorded in HRQoL over time for patients with burns. Significantly lower HRQoL was recorded for only a restricted number of patients, and mainly in mental dimensions, when they were compared with a reference group adjusted for age, sex, and importantly, coexisting conditions. The most important factor affecting most dimensions in HRQoL was unemployment. Given also the prevalence of psychological and psychiatric issues such as long-term psychiatric disease, our data support the hypothesis that worse HRQoL depends mainly on factors other than the burn itself. The results also highlight that 
long-term follow up and support of burn patients should focus on psychosocial issues and particularly the employment situation.

\section{Conflict of Interest}

The authors declare that there are no conflicts of interest. 


\section{References}

1. Pavoni V, Gianesello L, Paparella L, Buoninsegni LT, Barboni E. Outcome predictors and quality of life of severe burn patients admitted to intensive care unit. Scandinavian Journal of Trauma Resuscitation and Emergency Medicine 2010;18:24.

2. Moi AL, Wentzel-Larsen T, Salemark L, Wahl AK, Hanestad BR. Impaired generic health status but perception of good quality of life in survivors of burn injury. Journal of Trauma 2006;61(4):961-8.

3. Overgaard M, Hoyer CB, Christensen EF. Long-term survival and health-related quality of life 6 to 9 years after trauma. Journal of Trauma 2011;71(2):435-41.

4. van Loey N, van Beeck E, Faber B, van de Schoot R, Bremer M. Health-related quality of life after burns: A prospective multicentre cohort study with 18 months follow-up. Journal of Trauma 2011;72 (2):513-20.

5. Dyster-Aas J, Willebrand M, Wikehult B, Gerdin B, Ekselius L. Major depression and posttraumatic stress disorder symptoms following severe burn injury in relation to lifetime psychiatric morbidity. Journal of Trauma 2008;64:1349-56.

6. Oster C, Willebrand M, Ekselius L. Health-related quality of life 2 years to 7 years after burn injury. Journal of Trauma 2011;71(5):1435-41.

7. Orwelius L, Nordlund A, Nordlund P, Simonsson E, Bäckman C, Samuelsson A, Sjoberg

F.. Pre-existing disease: the most important factor for health related quality of life long-term after critical illness: a prospective, longitudinal, multicentre trial. Critical Care 2010;14:R67:doi:10.1186/cc8967

8. Ware JE, Jr., Sherbourne CD. The MOS 36-item short-form health survey (SF-36). I.

Conceptual framework and item selection. Medicine Care 1992;30(6):473-83.

9. The American Burn Association - online version http://www.ameriburn.org/.

10. Ekberg K, Noorlind Brage H, Dastserri ME. Östgötens hälsa och miljö (Health and

Environment 2000 in Östergötland) Centre for Public Health, County Council of

Östergötland, Sweden (In Swedish); 2000.

11. Sullivan M, Karlsson J, Ware JE, Jr. The Swedish SF-36 Health Survey--I. Evaluation of data quality, scaling assumptions, reliability and construct validity across general populations in Sweden. Social Science and Medicine. 1995;41(10):1349-58.

12. Angus DC, Carlet J. Surviving intensive care: a report from the 2002 Brussels

Roundtable. Intensive Care Medicine 2003;29(3):368-77.

13. Edgar D, Dawson A, Hankey G, Phillips M, Wood F. Demonstration of the validity of the SF-36 for measurement of the temporal recovery of quality of life outcomes in burns survivors. Burns;36(7):1013-20.

14. First MB, Spitzer RL, Gibbon M, Williams JBW. Structured Clinical Interview for DSMIV Axis I Disorders, Clinical Version, (SCID-CV). Washington, D.C: American Psychiatric Press, Inc.; 1996.

15. Orwelius L, Nordlund A, Edell-Gustafsson U, Simonsson E, Nordlund P, Kristenson M, Bendtsen P, Sjoberg F.. Role of preexisting disease in patients' perceptions of health-related quality of life after intensive care. Critical Care Medicine 2005;33(7):1557-64.

16. Ware J, Kosinski M, Dewey J. How to score version 2 of the SF-36 health survey. Rhode Island, USA: Quality Metric Incorporated; Lincoln, Ed.; 2001

17. Fauerbach JA, Lawrence J, Haythornthwaite J, McGuire M, Munster A. Preinjury psychiatric illness and postinjury adjustment in adult burn survivors. Psychosomatics 1996;37(6):547-55.

18. Lawrence JW, Fauerbach JA. Personality, coping, chronic stress, social support and PTSD symptoms among adult burn survivors: a path analysis. Journal of Burn Care and Rehabilitation 2003;24(1):63-72. 
19. Nordström A, Bodlund O. Every third patient in primary care suffers from depression, anxiety or alcohol problems. Nordic Journal of Psychiatry 2008;62:250-5.

20. Akerlund E, Huss FR, Sjoberg F. Burns in Sweden: an analysis of 24,538 cases during the period 1987-2004. Burns 2007;33(1):31-6. 
Table 1 Clinical details

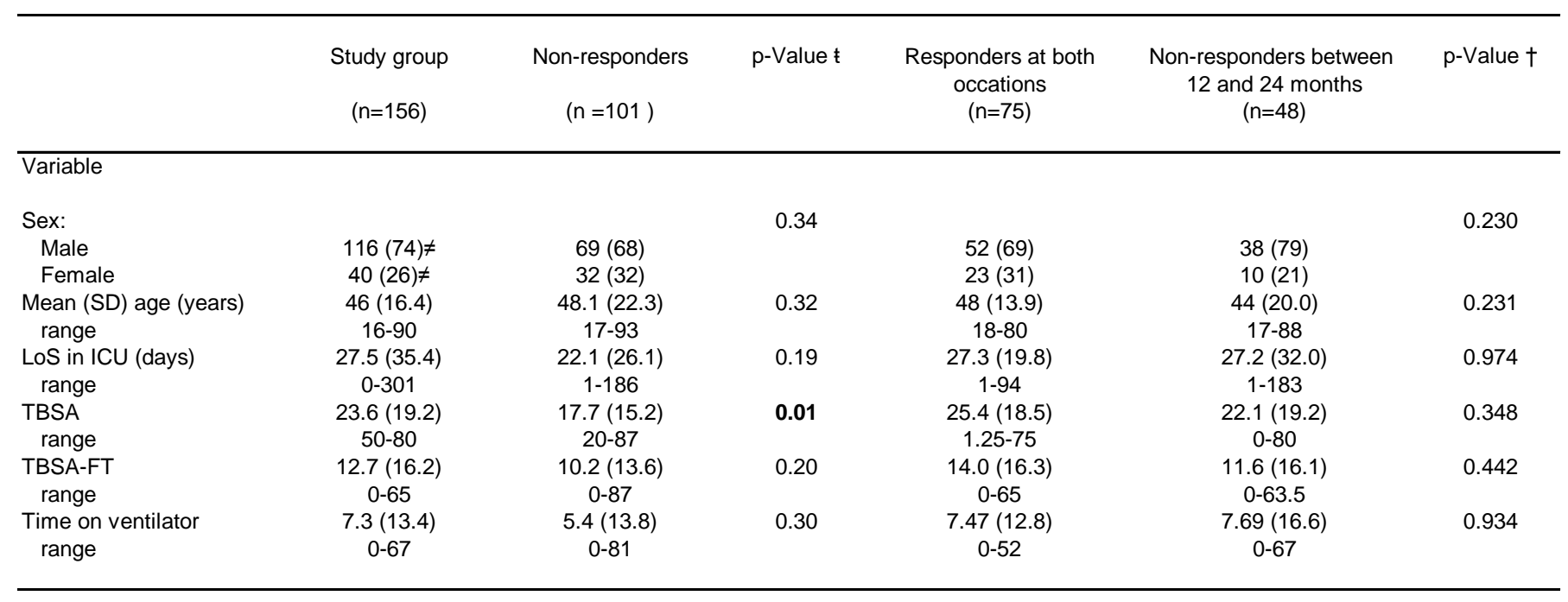

\# Missing value for 3 patients $(n=153)$

‡ between groups answered at 12 months and non-responders; † between groups answered at both occations and withdrawals beween 12 and 24 months TBSA; Total Body Surface Area, TBSA-FT; Total Body Surface Area Full Thickness, LoS; lenght of stay

Data are number (\%) or mean (SD) 
Table 2 Sociodemographic data for the study group and the reference group Data are number (\%) unless otherwise stated

\begin{tabular}{|c|c|c|c|}
\hline Characteristic & $\begin{array}{l}\text { Study group } \\
\quad(n=156)\end{array}$ & $\begin{array}{c}\text { Reference group } \\
(n=6093)\end{array}$ & p-value \\
\hline Mean (SD) age & $46(16.5)$ & $46(15.1)$ & 0.673 \\
\hline Male gender & $116(74) \ddagger$ & $2822(46)$ & $<0.001$ \\
\hline \multicolumn{4}{|l|}{ Education } \\
\hline Compulsory school only & $47(30)$ & $1881(31)$ & 0.843 \\
\hline High school/university & $18(12)$ & $1350(22)$ & 0.002 \\
\hline Marital status & & & $<0.001$ \\
\hline Single & $72(46)$ & $1312(22)$ & \\
\hline Married/cohabit & $72(46)$ & $4414(74)$ & \\
\hline Widow/widower & $12(8)$ & $275(5)$ & \\
\hline Born in Sweden & $137(90)$ & $5494(91)$ & 0.432 \\
\hline Employment before ICU stay & & & $<0.001$ \\
\hline Employed/leader & $97(63)$ & $3538(58)$ & \\
\hline Retired & $34(22)$ & $1132(19)$ & \\
\hline Other & $24(15)$ & $1423(23)$ & \\
\hline \multicolumn{4}{|l|}{12 months after ICU } \\
\hline Employed/leader & $77(49)$ & & \\
\hline Retired & $39(25)$ & & \\
\hline Other & $40(26)$ & & \\
\hline Pre-existing disease & $71(46)$ & $1707(28)$ & $<0.001$ \\
\hline Psychiatric disease & $22(14.1)$ & $99(1.6)$ & \\
\hline Asthma/allergy & $14(9.0)$ & $146(2.4)$ & \\
\hline Heart failure & $15(9.6)$ & 810 (13.3) & \\
\hline Neurologic disease & $7(4.5)$ & $72(1.2)$ & \\
\hline Diabetes & $4(2.6)$ & $95(1.6)$ & \\
\hline Gastrointestinal disease & $4(2.6)$ & $306(5.0)$ & \\
\hline Cancer & $2(1.3)$ & $32(0.5)$ & \\
\hline Miscellaneous & $19(12.2)$ & $722(11.8)$ & \\
\hline \multicolumn{4}{|l|}{ No. of diseases } \\
\hline 0 & $85(54.5)$ & $4386(72)$ & \\
\hline 1 & $60(38.5)$ & $1411(23.2)$ & \\
\hline$>1$ & $11(7.0)$ & $296(4.8)$ & \\
\hline Sick before ICU stay & $7(4.5)$ & & \\
\hline Sick leave & $38(24.5)$ & 75 (1.2) & \\
\hline
\end{tabular}

ŁMissing value for 3 patients 
Table 3 Proportions of the ICU patients with SF-36 score 2SD below the reference group lower level adjusted for age and sex

Without comorbidity $(\mathrm{n}=85)$

Physical functioning

Physical role

Bodily pain

General health

Vitality

Social functioning

Emotional role

Mental health

\begin{tabular}{cccc}
$\mathrm{N}(\%)$ & range & mean & $\mathrm{SD}$ \\
\hline & & & \\
$4(5)$ & $24.8-29.3$ & 27.2 & 1.9 \\
$3(4)$ & $-0.45--0.01$ & -0.24 & 0.2 \\
$1(1)$ & $21.2-21.2$ & 21.2 & \\
$2(2)$ & $24.0-25.2$ & 24.6 & 0.8 \\
$7(8)$ & $2.3-18.1$ & 9.2 & 6.2 \\
$12(14)$ & $-2.4-37.5$ & 23.2 & 14.1 \\
$22(26)$ & $-7.3--2.6$ & -5.4 & 1.4 \\
$29(34)$ & $-14.1-35.9$ & 15.7 & 14.3
\end{tabular}

Comorbidity 1 disease $(n=60)$

Physical functioning

0

Physical role

Bodily pain

General health

Vitality

Social functioning

Emotional role

Mental health

Comorbidity $>1$ disease $(n=11)$

Physical functioning

Physical role

Bodily pain

General health

Vitality

Social functioning

Emotional role

Mental health

\section{0}

0

0
1 (2)

$3(5)$

14.5-14.5

14.5

$-13.3-4.8$

$-7.0$

10.2

$11(18)$

$-4.3-25.0$

10.5

13.1

$13(22)$

$-2.0--1.6$

$-1.8$

0.1

4 (7)

$-9.0-18.5$

10.6

13.2

2 (18)

$-8.0--0.2$

$-4.1$

5.5

0

0

1(9)

0.34-0.34

0.34

2 (18)

10.5-10.7

10.6

0.13

2 (18)

$-1.4-15.8$

7.2

12.2 
Table 4 Descriptive data for the burn patients with SF-36 score 2SD under the reference group lower level in at least one of the SF-36 eight dimensions comparison with the burn patients with normal SF-36 score Data are number (\%) unless otherwise stated

\begin{tabular}{|c|c|c|c|}
\hline & $\begin{array}{l}\text { Patients with normal level } \\
\qquad(\mathrm{n}=96)\end{array}$ & $\begin{array}{l}\text { Patients with low level } \\
\qquad(\mathrm{n}=60)\end{array}$ & p-value \\
\hline$\overline{\text { Age years mean }(\mathrm{SD})}$ & $46(18.4)$ & $46(13.1)$ & 0.960 \\
\hline Sex, male & $66(71.0) \ddagger$ & 47 (78.3) & 0.311 \\
\hline TBSA & $21.8(17.8)$ & $27.7(18.5)$ & 0.052 \\
\hline TBSA-FT & $10.7(13.2)$ & $16.6(18.4)$ & 0.023 \\
\hline Stay in ICU, hours mean (SD) & $20.8(16.8)$ & $36.2(35.7)$ & $<0.001$ \\
\hline Time on ventilator, hours mean (SD) & $5.1(9.9)$ & $10.4(17.4)$ & 0.016 \\
\hline Marital state & & & 0.040 \\
\hline Married/cohabit & $39(40.6)$ & $33(55)$ & \\
\hline Single & $46(47.9)$ & 26 (43.3) & \\
\hline Widow / widower & $11(11.5)$ & $1(1.7)$ & \\
\hline Employment before ICU * & & & 0.226 \\
\hline Employed/leader & $56(58.9)$ & $41(68.3)$ & \\
\hline Retired & $23(24.2)$ & $11(18.3)$ & \\
\hline Other & $16(16.7)$ & $8(13.3)$ & \\
\hline Sick leave before ICU & $2(2.1)$ & $5(8.3)$ & 0.067 \\
\hline Born in Sweden * & $83(88.3)$ & $54(91.5)$ & 0.525 \\
\hline \multicolumn{4}{|l|}{ Education } \\
\hline Higher than compulsory school & $65(67.7)$ & $44(73.3)$ & 0.456 \\
\hline High School/university * & $11(11.6)$ & $7(11.7)$ & 0.987 \\
\hline Mortality during the study & $2(2.1)$ & $2(3.3)$ & 0.631 \\
\hline
\end{tabular}

${ }^{*}$ Not all patients answered the question

‡ Missing value for 3 patients 
Table 5a Impact of different factors on HRQoL physical dimensions, (SF-36 mean) at 12 months Linear multiple regression analysis. Data are p-value, B (95\% Confidence Interval for B )

\begin{tabular}{|c|c|c|c|c|}
\hline Variable & $\begin{array}{l}\text { Physical } \\
\text { functioning }\end{array}$ & $\begin{array}{l}\text { Physical } \\
\text { role }\end{array}$ & $\begin{array}{l}\text { Bodily } \\
\text { pain }\end{array}$ & $\begin{array}{c}\text { General } \\
\text { health }\end{array}$ \\
\hline \multirow[t]{2}{*}{ TBSA } & 0.436 & 0.396 & $<0.001$ & 0.735 \\
\hline & $-0.13(-0.45$ to 0.20$)$ & $-0.24(-0.80$ to 0.32$)$ & $-0.47(-0.71$ to -0.23$)$ & $-0.05(-0.36$ to 0.25$)$ \\
\hline \multirow[t]{2}{*}{ TBSA-FT } & $<0.001$ & 0.173 & 0.282 & 0.091 \\
\hline & $-0.57(-0.82$ to -0.32$)$ & $-0.46(-1.12$ to 0.20$)$ & $-0.22(-0.61$ to 0.18$)$ & $-0.33(-0.72$ to 0.05$)$ \\
\hline \multirow[t]{2}{*}{ Length of stay } & 0.173 & $<0.001$ & 0.843 & 0.001 \\
\hline & $-0.17(-0.41$ to 0.08$)$ & $-0.65(-0.90$ to -0.41$)$ & $0.03(-0.27$ to 0.33$)$ & $-0.23(-0.36$ to -0.09$)$ \\
\hline \multirow[t]{2}{*}{ Time on ventilator } & 0.500 & 0.628 & 0.051 & 0.263 \\
\hline & $-0.17(-0.66$ to 0.32$)$ & $0.20(-0.62$ to 1.03$)$ & $0.49(-0.003$ to 0.98$)$ & $0.22(-0.17$ to 0.62$)$ \\
\hline Pre-existing disease & 0.147 & 0.684 & 0.069 & 0.004 \\
\hline Yes/No & $-4.81(-11.33$ to 1.71$)$ & $-2.46(-14.37$ to 9.46$)$ & $-6.59(-13.72$ to 0.53$)$ & $-8.72(-14.57$ to -2.87$)$ \\
\hline Sex & 0.235 & 0.062 & 0.245 & 0.104 \\
\hline Male/Female & $-5.57(-14.78$ to 3.65$)$ & $-14.40(-29.52$ to 0.72$)$ & $-5.91(-15.92$ to 4.10$)$ & $-6.84(-15.09$ to 1.41$)$ \\
\hline \multirow[t]{2}{*}{ Age } & $<0.001$ & 0.004 & 0.007 & $<0.001$ \\
\hline & $-0.52(-0.77$ to -0.28$)$ & $-0.59(-0.99$ to -0.19$)$ & $-0.38(-0.65$ to -0.11$)$ & $-0.47(-0.73$ to -0.22$)$ \\
\hline Sick leave now & 0.643 & 0.905 & 0.824 & 0.239 \\
\hline Yes/No & $1.19(-3.86$ to 6.23$)$ & $0.49(-7.60$ to 8.57$)$ & $0.61(-4.80$ to 6.02$)$ & $2.55(-1.71$ to 6.82$)$ \\
\hline Employment now & 0.016 & 0.161 & 0.014 & 0.022 \\
\hline Yes/No & $-9.86(-17.83$ to -1.90$)$ & $-10.10(-24.25$ to 4.06$)$ & $-10.91(-19.55$ to -2.27$)$ & $-8.68(-16.11$ to -1.25$)$ \\
\hline \multicolumn{5}{|c|}{ 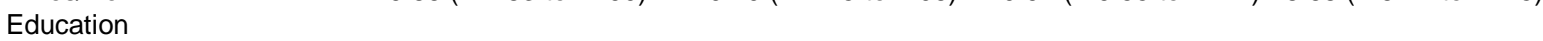 } \\
\hline Higher than basic school & 0.408 & 0.771 & 0.288 & 0.829 \\
\hline Yes/No & $3.82(-5.29$ to 12.93$)$ & $2.45(-14.19$ to 19.09$)$ & $5.41(-4.63$ to 15.46$)$ & $0.93(-7.61$ to 9.48$)$ \\
\hline High school/university & 0.647 & 0.335 & 0.195 & 0.756 \\
\hline Yes/No & $3.08(-10.20$ to 16.35$)$ & $10.07(-10.50$ to 30.65$)$ & $-9.08(-22.84$ to 4.69$)$ & $-1.82(-13.40$ to 9.75$)$ \\
\hline Marital state & 0.984 & 0.736 & 0.679 & 0.865 \\
\hline Married, cohabit/Single & $-0.09(-8.87$ to 8.69$)$ & $2.56(-12.44$ to 17.55$)$ & $1.94(-7.31$ to 11.18$)$ & $0.67(-7.14$ to 8.48$)$ \\
\hline
\end{tabular}

Adjusted for age, and sex; Beta, unstandardized coefficient

HRQoL; Health related quality of life, SF-36 short form health outcome, TBSA; Total body surface area,

TBSA-FT; Total body surface area full thickness 
Table 5b Impact of different factors on HRQoL mental dimensions, (SF-36 mean) at 12 months Linear multiple regression analysis. Data are $p$-value, B (95\% Confidence Interval for B )

\begin{tabular}{|c|c|c|c|c|}
\hline Variable & Vitality & $\begin{array}{c}\text { Social } \\
\text { functioning }\end{array}$ & $\begin{array}{l}\text { Emotional } \\
\text { role }\end{array}$ & $\begin{array}{l}\text { Mental } \\
\text { health }\end{array}$ \\
\hline \multirow[t]{2}{*}{ TBSA } & 0.437 & 0.696 & 0.151 & 0.112 \\
\hline & $0.12(-0.19$ to 0.44$)$ & $0.08(-0.33$ to 0.50$)$ & $0.431(-0.15$ to 0.98$)$ & $0.24(-0.56$ to 0.53$)$ \\
\hline \multirow[t]{2}{*}{ TBSA-FT } & 0.002 & 0.371 & 0.094 & 0.021 \\
\hline & $-0.38(-0.61$ to -0.15$)$ & $-0.21(-0.67$ to 0.25$)$ & $-0.37(-0.80$ to 0.06$)$ & $-0.27(-0.49$ to -0.04$)$ \\
\hline \multirow[t]{2}{*}{ Length of stay } & 0.215 & $<0.001$ & 0.554 & 0.351 \\
\hline & $-0.16(-0.41$ to 0.09$)$ & $-0.39(-0.56$ to -0.22$)$ & $-0.13(-0.57$ to 0.31$)$ & $-0.11(-0.34$ to 0.12$)$ \\
\hline \multirow[t]{2}{*}{ Time on ventilator } & 0.268 & 0.872 & 0.527 & 0.711 \\
\hline & $0.24(-0.19$ to 0.66$)$ & $-0.05(-0.66$ to 0.56$)$ & $0.28(-0.59$ to 1.14$)$ & $0.08(-0.37$ to 0.54$)$ \\
\hline Pre-existing disease & 0.029 & 0.383 & 0.844 & 0.029 \\
\hline Yes/No & $-6.95(-13.16$ to -0.74$)$ & $-3.53(-11.52$ to 4.46$)$ & $1.25(-11.27$ to 13.77$)$ & 7.74 (0.80 to 14.69$)$ \\
\hline Sex & 0.271 & 0.551 & 0.401 & 0.405 \\
\hline Male/Female & $-5.03(-14.03$ to 3.96$)$ & $-3.24(-13.98$ to 7.49$)$ & $-6.79(-22.70$ to 9.13$)$ & $-3.58(-12.05$ to 4.89$)$ \\
\hline \multirow[t]{2}{*}{ Age } & 0.010 & 0.264 & 0.306 & 0.434 \\
\hline & $-0.35(-0.62$ to -0.08$)$ & $-0.16(-0.45$ to 0.12$)$ & $-0.23(-0.68$ to 2.21$)$ & $0.09(-0.13$ to 0.30$)$ \\
\hline Sick leave now & 0.038 & 0.670 & 0.587 & 0.423 \\
\hline Yes/No & $4.67(0.26$ to 9.09$)$ & $1.15(-4.19$ to 6.50$)$ & $2.33(6.14$ to 10.82$)$ & $1.75(-2.56$ to 6.06$)$ \\
\hline Employment now & 0.010 & 0.127 & 0.002 & 0.015 \\
\hline Yes/No & $-10.16(-17.81$ to -2.51$)$ & $-7.43(-16.99$ to 2.13$)$ & $-22.58(-36.68$ to -8.49$)$ & $-9.02(-16.26$ to -1.79$)$ \\
\hline \multicolumn{5}{|c|}{ 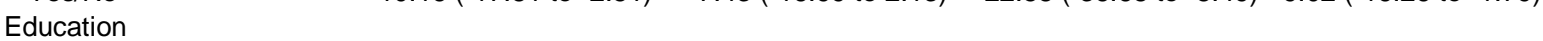 } \\
\hline Higher than basic school & 0.079 & 0.162 & 0.982 & 0.386 \\
\hline Yes/No & $7.72(-0.91$ to 16.35$)$ & $7.37(-3.00$ to 17.75$)$ & $-0.19(-16.82$ to 16.44$)$ & $3.69(-4.70$ to 12.09$)$ \\
\hline High school/university & 0.760 & 0.686 & 0.331 & 0.100 \\
\hline Yes/No & $-1.95(-14.57$ to 10.66$)$ & $3.31(-12.88$ to 19.51$)$ & $10.90(-11.20$ to 33.01$)$ & $9.30(-1.80$ to 20.40$)$ \\
\hline Marital state & 0.454 & 0.399 & 0.941 & 0.340 \\
\hline Married, cohabit/Single & $3.06(-5.00$ to 11.12$)$ & $4.30(-5.75$ to 14.35$)$ & $-0.57(-15.77$ to 14.64$)$ & $3.65(-3.88$ to 11.19$)$ \\
\hline
\end{tabular}

Adjusted for age, and sex; Beta, unstandardized coefficient

HRQoL; Health related quality of life, SF-36 short form health outcome, TBSA; Total body surface area,

TBSA-FT; Total body surface area full thickness 


\section{Figure legends}

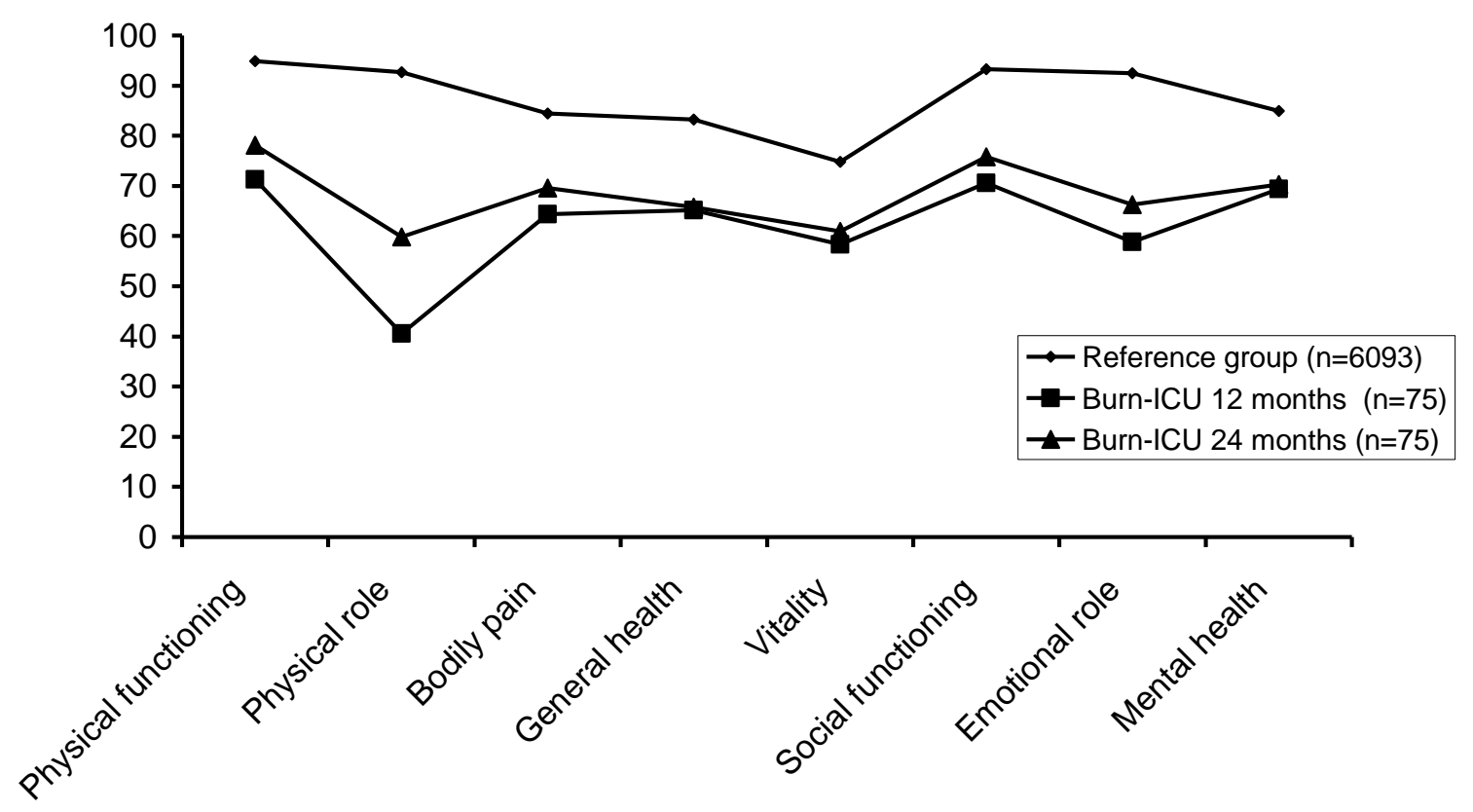

Health-related quality of life (SF-36): comparison of the reference group $(n=6093)$ with the burned patients 12 and 24 months after the burn $(n=75)$. 